\title{
Investigating social processes that underpin local flood risk management action
}

Rosalind H Bark (corresponding author)

School of Environmental Sciences, University of East Anglia, Norwich, NR4 7TJ,

R.Bark@uea.ac.uk

Mike C. Acreman, Research Fellow, Centre for Ecology \& Hydrology, Crowmarsh Gifford, Wallingford, OX10 8BB, man@ceh.ac.uk

\section{Highlights}

- As soft FRM (sFRM) is more widely implemented, this brings in social elements

- Underlying social processes (SPs) can strengthen sFRM, joining-up catchments

- The SPs of Accommodation, Coordination, and Acculturation foster shared objectives

- Inclusive practices of visioning and partnering are key activities for local groups

\section{Abstract}

As climate change erodes current levels of flood protection in the UK and government investment in 'hard' flood risk management (hFRM) is rationed by cost-benefit ratios, the option for many communities at-risk is to implement local 'soft' FRM (sFRM). The frequency of widespread flooding generates an added urgency to understand how to support sFRM. Using a case study and qualitative analysis, we explore social processes (SPs), such as acculturation, that drive stakeholder adaptation to be more flood resilient. We conceptualise the status quo beleaguered by conflict and competition and propose practices of accommodation and cooperation that can support shared objectives and responsibility that strengthen SFRM. Our conceptual model is mapped on a stylised catchment to illustrate how SPs underpin sFRM interventions that join-up the catchment in wholescape thinking. The transferable learning is that there are group behaviours and inclusive practices that can initiate and support local sFRM.

Key words: social processes, flood risk management, soft FRM, wholescape thinking, visionmaking

\section{Introduction}

The 2019-20 winter in the UK has filled media with images of flooded communities, farmland, and infrastructure accompanied by politicians pressed-hard to do more for affected communities and to prevent future flooding. Calls to increase investment in hFRM interventions, i.e. structural civil engineering such as embankments, dams and flow diversions, follow such flood disasters. Yet, except in areas that are densely populated, have critical infrastructure, or Grade 1 classified agricultural land; hFRM solutions can be too expensive and are unlikely to be the preferred government option (NAO, 2014). This raises the profile of SFRM, i.e. tree planting, woody debris dams, floodplain storage, in the UK and elsewhere. Miao and Popp (2014) in a review of 25 years of disaster data from 28 
countries find that many nations are investing in SFRM and others note a re-emergence of sFRM for adaptation in delta regions (Wesselink et al., 2015).

SFRM is therefore of growing relevance to the success of flood risk adaptation policy. Adaptation can be characterised as reactive or anticipatory (Fankhauser et al., 1999). Miao and Popp (2014) find reactive responses are greater the more severe and recent the flood and that anticipatory measures can be spurred by floods in nearby countries. Moreover, there is evidence of international learning in particular around sFRM (Wesselink et al., 2015). Both papers emphasise the opportunity to support anticipatory adaptation in the interval between floods.

Penning-Rowsell et al. (2006) in a review of four UK floods found "windows of opportunity" are opened by crisis disruption and that this interval between floods is crucial for the development of proactive and strategic FRM policy. Through evaluation of the public and professional flood discourse in these intervals they find early "signals" of policy change. Two key messages are that: (1) existing ideas from flood discourses are adopted into policy; and therefore, (2) policy makers and other stakeholders could prepare for policy change.

A more proactive/strategic FRM approach fits with a second characterisation of adaptation as either autonomous or planned (Fankhauser et al., 1999). This is critical in the UK as climate change erodes current levels of flood protection and more households, businesses, farmland and infrastructure are exposed to flood damage and disruption risk (HM Government 2016). Already systemic failures in the UK's FRM policy have been exposed in a series of disruptive floods, including widespread summer floods in 2007 and winter floods in Somerset in 2013/14, in northern England and southern Scotland in 2015, and in the Midlands and northern England in 2019/20.

\subsection{FRM and nature-based solutions (NBS)}

In exploring contemporary FRM the rise of NBS is unmistakeable. The European Union's (EU) Floods Directive (Directive 2007/60/EC) sets out legislation for Member Countries to: undertake long-term planning with FRM Plans; coordinate implementation at the river basin level; consult with stakeholders; and focus on prevention, protection and preparedness, including options to restore or maintain floodplains. Furthermore, implementation of it must coordinate with the environmental objectives of EU's Water Framework Directive (WFD, Directive 2000/60/EC).

NBS such as planting trees features in the UK government's manifesto, but such interventions are long-term and require a paradigm shift for the Environment Agency (EA), England's flood management agency, accustomed to FRM based on hFRM guided by hydraulic models, traditional risk analysis, and cost-benefit ratios (Porter and Demeritt, 2012; EA, 2014; NAO, 2014). The potential effectiveness of some natural features for FRM is well-documented, such as wetlands (Bullock and Acreman, 2003; Acreman and Holden, 2013) and woodlands (Stratford et al., 2017). NBS at the catchment-scale may score winwins, for instance, storing floodwaters in floodplain wetlands to protect critical downstream infrastructure and homes can also contribute to floodplain biodiversity (Acreman et al., 2003; Duranel et al., 2007; Acreman et al., 2011). 


\subsection{FRM Devolution}

The rise of NBS has contributed to a more devolved FRM. In devolution, local stakeholders have more power and responsibility and can potentially drive adaptation, i.e. "local floods need local responses" (Penning-Rowsell and Johnson 2015, p139). However, Thaler and Priest (2014) assessing partnership funding and localism in England, find devolution does not always live-up to its promise. That is politicisation of FRM decisions can occur at all levels of government. They find that "devolved responsibility" (ibid, p140) to English communities is often partial and has not generally included policy-making and funding. Furthermore, tensions exist on how to achieve engagement, coordination and implementation across scales.

\subsection{Devolved FRM Implementation}

The focus of devolved FRM research on policy and governance has only more recently extended to implementation. McCarthy et al. (2018) discussed approaches in implementation and Henstra et al. (2019, p2) referred to "sharing FRM responsibility". They argue sharing responsibility has several advantages including providing "an incentive for individuals and groups to take independent action to mitigate their flood risk and prepare for recovery after a flood." Penning-Rowsell and Johnson (2015, p139) concur; "individuals and groups exercise power, not organisations per se".

SFRM, through adding these social dimensions, increases the scope for proactive and planned adaptation where choices might involve conflict resolution, participatory decisionmaking, and community networks. This paper addresses some of the gaps in research on sFRM implementation by investigating SPs that underpin group action. Specifically, we deliberate "focused" (social) interaction, i.e. of groups of stakeholders around a common goal. Group activity suggests underlying SPs based on repeated patterns of social interactions. An early categorisation of SPs by Bardis (1979) comprised: acculturation, i.e. cultural change; accommodation, i.e. mutual adjustment to group conflict; assimilation, i.e. one-way or mutual absorption; cooperation, i.e. intentionally combining activities; competition, i.e. struggle over scarce 'goods'; and conflict, i.e. attempts to thwart one another's goals. These same SPs are directly or indirectly discussed in FRM research, e.g. conflict, competition, cooperation (Thaler et al., 2017), accommodation (Penning-Rowsell et al., 2006), acculturation, assimilation (Wesselink et al., 2015), and so we adopt them here.

The paper is structured as follows. We introduce a case study that has representative, critical and revelatory characteristics (Yin, 2009). The methods present our conceptual framework, data and qualitative analysis. The results are presented and the implications and transferability of the research are discussed.

\section{Case study}

\subsection{Somerset Levels \& Moors (SL\&M)}


People, land-use and hydrological processes have shaped the SL\&M landscape over thousands of years. It is mostly low-level, covering around 65,000 ha, see Figure 1 . The gradients of the three rivers (the Axe, Brue and Parrett) that drain through the SL\&M are low so rainfall falling on the upstream catchments does not naturally drain rapidly to the sea making the land flood-prone and marshy. Centuries in the making, a network of drainage channels and associated infrastructure moves water around to and from the rivers, to support lowland agriculture and assist flood management (Acreman et al., 2011).

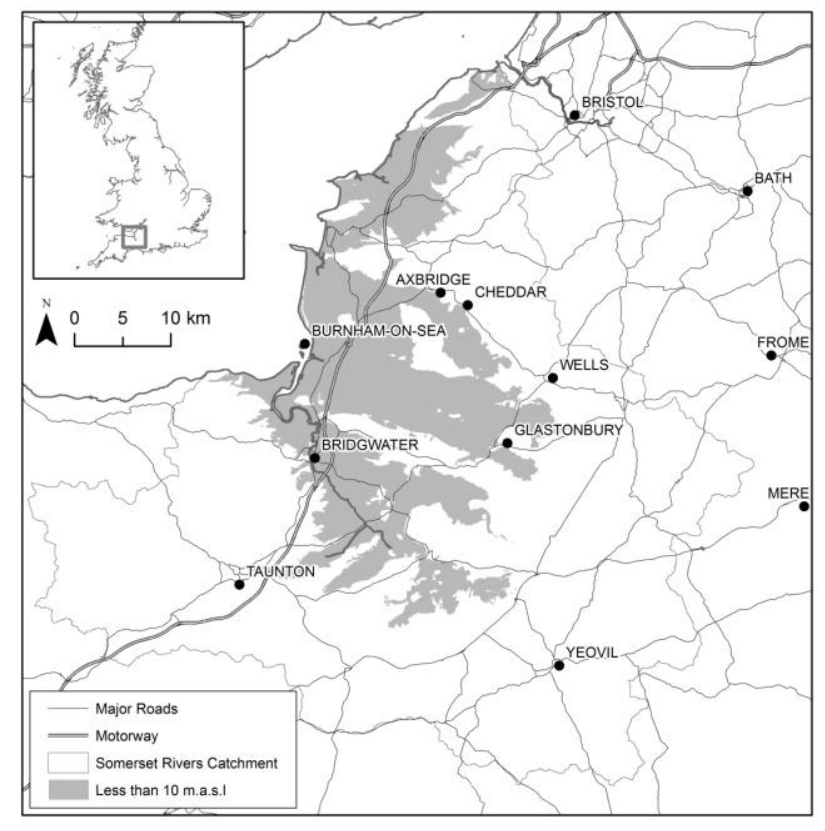

Figure 1: Map of SL\&M with low-lying areas shaded

This landscape has created a distinct environment that has been designated as a wetland of international importance under the Ramsar Convention for its birdlife, invertebrates and plants. It has also been recognised as one of 159 designated National Character Areas (NCA) in England by Natural England (NE, 2013) and for many local people the landscape is central to cultural identity.

Agricultural water level management (WLM) infrastructure is extensive, including large pumping stations, sluice gates, weirs and penning boards. The Somerset Drainage Boards Consortium (SDBC) manages this infrastructure for productive mixed arable farming and grazing livestock. This has created a checkerboard of WLM regimes across the floodplain to meet the needs of different farming systems. In general, the SDBC raises water levels in summer and lowers them in winter (opposite to the natural regime) and evacuates floodwaters (Acreman et al., 2011). SDBC WLM has raised the value of agricultural land (and reduced the value of minimal input floodplain grazing vis-à-vis mixed arable) and boosted the local economy, but this has also increased the vulnerability of the area to flooding and economic damages, e.g. devastating spring floods in 2012 caused an estimated $f 10$ million in costs to farmers and local businesses (Morris and Brewin, 2014). Much of the land is now owned by nature organisations (such as NE and Royal Society for the Protection of Birds - RSPB) who have re-instated a more natural hydrological regime with winter flooding. Recent initiatives, such as Living Landscapes 
(www.somersetwildlife.org), propose consistent broad-scale WLM, arguing that healthy ecosystems underpin productive farming, biodiversity, and quality of life.

The winter floods of 2013/14 flooded $\sim 15,000$ ha of land, $\sim 165$ homes, cut off villages for months and disrupted local and regional (major roads and railways cross the area) transportation networks. An estimate of total direct and indirect damage costs is $£ 118$ million (SRA, 2015). Increased flood risk and vulnerability threatens to expose path dependencies (Staveren and Tatenhove, 2016), for instance around technical choices governing river flow and ditch WLM, which has converted floodplain habitats through drainage to agricultural land and has in turn reduced those areas of the floodplain managed to store floodwaters.

\subsection{Governance arrangements}

Prior to the floods, there was a drive to restore the ecological status of the rivers to meet the EU WFD by allowing natural processes and reducing management and infrastructure. In particular regular dredging of river channels to better evacuate flood waters was significantly reduced. Recognition of the increasing intentional inundation of nature reserves led many to conclude that the landscape was being managed for wildlife at the expense of people, fomenting political tensions. The national government response to the 2013/14 floods was to reverse decades of reduced investment in water management infrastructure (Smith et al., 2016), contributing f20 million (US\$25 million) to the 20-year SL\&M Flood Action Plan (FAP) (FAP 2014; UK Government 2014). This funding spurred large-scale, FRM engineering projects to increase flood protection in the County, e.g. raising roads and diverting floodwater through culverts and increased dredging of rivers and agricultural drains (SRA, 2017). Also FAP-funded was a feasibility assessment for a tidal barrier at Bridgwater, one of the main urban areas in Somerset. A Community Infrastructure Levy will fund construction costs (SDC, 2014).

Funding set aside for the development of a Somerset rivers board was a fraction of the FAP funding $(£ 100,000)$. Yet, established in January 2015 , the Somerset Rivers Authority (SRA) is the only such body in England. It has partners from across local, regional and national bodies. The success of such decentralised FRM governance is conditional on the capacity to fund interventions (Thaler and Priest, 2014).

Critically, the national government granted Somerset County Council (SCC) tax-raising powers. Council Tax is levied on all homes in England, Wales and Scotland and is based on property value bands. SCC raised rates by $1.25 \%$ across all bands. Around $f 2.8$ million is raised annually and funds an array of SRA projects, including local resilience projects, aligned with the FAP, across the entire County.

Other local institutions are the Somerset Water Management Partnership (SWMP). Established in 2007 it meets four times a year and partners include the EA, SCC, Wessex Water, Somerset Wildlife Trust (SWT), NE, SDBC, RSPB, Farming \& Wildlife Advisory GroupSouth West (FWAG-SW), individual farmers, and councillors. It provides a forum for debate, networking, learning, updates and communication and aims to promote a whole of catchment approach to water management and flood prevention. Another partnership 
group, the Somerset Catchment Partnership (SCP), is hosted by FWAG-SW. It is dedicated to promoting the Catchment Based Approach ( $\mathrm{CaBA}$ ) of working at the catchment scale (Defra 2013).

\section{Methodology}

This paper is based on findings from a larger European Commission-funded project. The project's aims were to evaluate opportunities and obstacles to catchment-based approaches for FRM in the UK. The project received research ethics approval (University of Leeds AREA 14-096 and Amendments). A series of site visits, meetings with stakeholders to discuss NBS and key issues in SL\&M, and regular (invited) attendance at the SWMP meetings during 2015-2018 informed the development of six questions (see Appendix) and the design of two stakeholder workshops.

\subsection{Case study selection}

Yin (2009) suggests five rationales for a single (detailed) case study design for social science research, where the case is a: critical, unique, representative, revelatory, or longitudinal case. Somerset, particularly the SL\&M, has a long history of flooding, strong local responses, and is pivotal to the national discourse around FRM policy. In terms of rationales it is a representative case of lowland flooding and a critical case for national FRM policy. We also suggest that it is a revelatory case that can reveal hitherto unexplored SPs in SFRM.

\subsection{Conceptual framework}

SPs can be process-oriented or outcome-oriented (Grimm et al. 2013). In developing a conceptual framework we focus on process-oriented interventions that support catchment-scale sFRM. Whereas, Seher and Löschner (2018) in their research on FRM governance in Austria explore both vertical and horizontal coordination, here our interest is what SPs support SFRM interventions which work with underlying flood hydrology, where upstream-downstream connectivity and floodplain connectivity are fundamental. Achieving these two elements of connectivity is key to what Acreman et al. (2018) coin wholescape thinking.

In this conceptualisation we consider: (1) dominant SPs when groups do not consider others in the catchment; (2) types of sFRM interventions that can join-up a catchment (and SL\&M examples, e.g. HtoL); and (3) SPs that either contribute to, or support these sFRM interventions. 


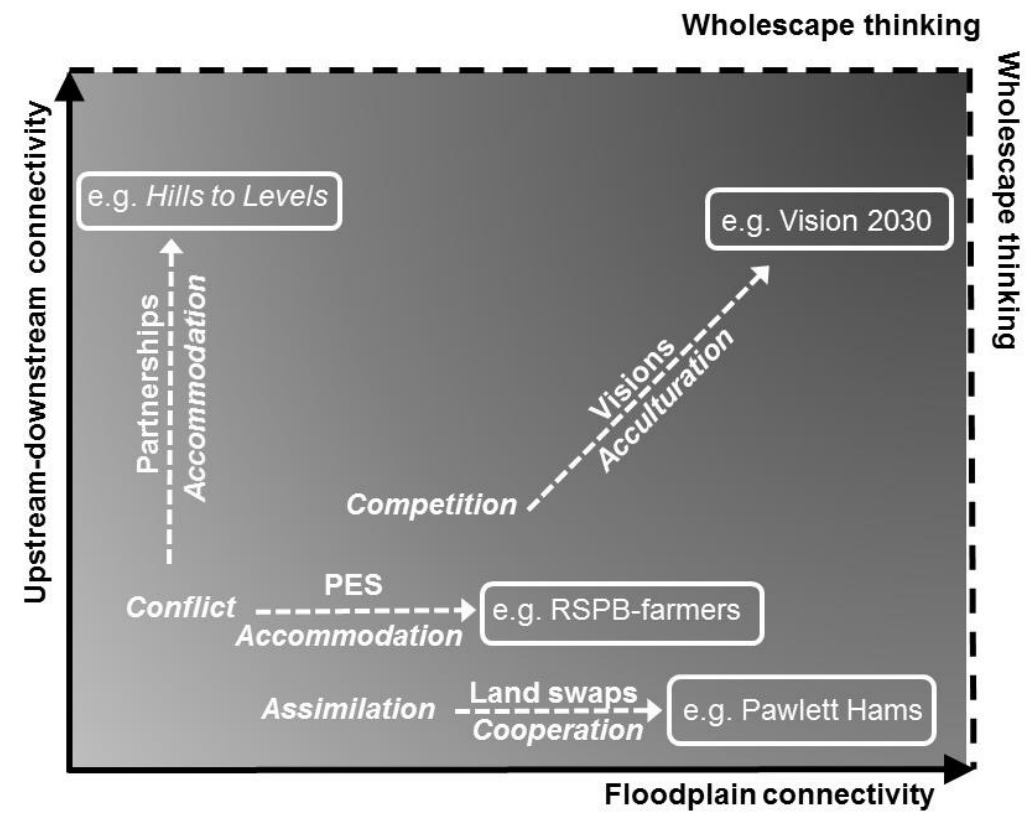

Figure 2: Conceptualisation of SPs and pathways in a stylised SL\&M catchment. The vertical/horizontal axis represents upstream-downstream/floodplain connectivity and the diagonal line represents increasing wholescape thinking.

The bottom left corner represents latent tension - Conflict, Competition, and Assimilation - that works against wholsescape thinking. This tension per se may not be a 'bad' but could in some instances be viewed as a precursor to other SPs that can support interventions that improve catchment connectivity and wholescape thinking. Using examples from SL\&M, we map four SFRM interventions - partnerships, visions, PES, land swaps - that can improve catchment connectivity. New group behaviours and practices that support the design and trialling of interventions centre on Accommodation, Acculturation and Cooperation.

\subsection{Workshop data}

A series of key informant interviews with stakeholders in SL\&M, such as the Somerset Wildlife Trust and the IDB, plus FAP site visits to hard and soft infrastructure projects organised by the SRA, and our participation in SWMP meetings, informed the design of two stakeholder workshops that were run in Glastonbury, Somerset. An advantage of a workshop is the informality and opportunity for participants to network and discuss topics as a group. A disadvantage is that more in-depth responses could have been collected, e.g. using semi-structured interviews as in McCarthy et al. (2018) where thirteen practitioners shared their views on flood storage compensation. To provide flexibility, two half-day workshops were held on consecutive days in May 2017. An open invitation to the workshops was distributed through the SWMP and recipients were encouraged to circulate it through their networks. There were a total 11 workshop participants who represented a wide range of SL\&M stakeholders including farmers, regulatory authorities, the IDB, local councils, conservation groups and business. 
During the workshops each question was posed in order, the first author wrote verbatim ideas from participants formatted in bullet points on a flip chart and the second author facilitated participation. Afterwards responses were transcribed and shared with the participants of both workshops for review. No reviews were forthcoming.

A further eight respondents answered an online survey. This option was made available following a recommendation from Workshop 2 participants. It provided an opportunity for those unable to make either workshop to contribute to the discussion. The survey replicated the workshop questions and question order. It was developed using the BOS online survey tool and closed on 15 June 2017. The workshop and online data combined represents 19 stakeholder views. We cannot guarantee that the participants reflect all the views in the SL\&M only that diverse stakeholders were represented.

\subsection{Coding and Analysis}

Data was coded by the first author and later recoded to verify initial coding. Coding is a way to identify themes in qualitative data (Corbin and Strauss, 2010). Hereafter, codes are delineated with a capital letter. Codes were developed from the literature, e.g. Politicisation, Partnership, Localism (Thaler and Priest, 2014), the six SPs (Bardis, 1979), e.g. Assimilation, and through observation of the transcripts and online responses, e.g. Devolved Funds. Each bullet point from the workshops or text from the online survey could be coded for one or more codes, see below.

Soil improvement good value compared to dredging. [Workshop 1, Codes: Competition, Dredging]

Codes were analysed using the qualitative analysis software NVivo 12. NVivo 12 matrix queries (cross-tabulations) were used to explore the relationships between codes.

\section{Results}

Results comprise coding analysis, verbatim bullet points from the workshops or quotes from the online survey, and exploration of the conceptual model.

\subsection{Coding}

The most frequent codes were for Competition, Localism, Vision-making, and Conflict. The relationships between individual SPs is shown in Figure 3. Line thicknesses represent the number of codes. In general, codes on the left side/right side are most frequently: (1) coded with the opposite side; and (2) not coded with each other. These associations provide some support for the conceptual model, for example Assimilation - Cooperation. The outlier is that Assimilation and Competition were often coded together and suggest that these tensions are often linked, see Section 4.1.1. 


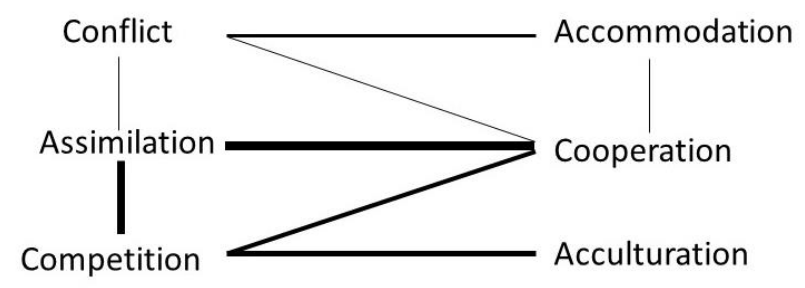

Figure 3: Matrix query results: Relationships between SPs. Line thicknesses represent number of codes.

Relationships between SPs and other codes are harder to discern. Partnerships was most frequently coded with Conflict and Floodplains with Competition, Acculturation, and Assimilation. Vision was coded with all six SPs and frequently coded (in order) with: Competition, Cooperation, Assimilation, Acculturation, and Conflict.

\subsection{SPs and sFRM}

Here we elaborate our results with respect to the conceptual pathways from Figure 2.

\subsubsection{Floodplain connectivity}

The dominant one-way Assimilation pressure in the SL\&M is the agglomeration of farms into larger, more intensive enterprises (NE, 2013). A consequence is reinforcement of WLM for drier floodplain conditions, which increases the opportunity cost of floodplain storage and wetland conservation and threatens the floodplain ecosystem. However, innovators in Somerset farming practise a new type of Assimilation based on mutual-Assimilation and Cooperation that improves floodplain connectivity.

Our first example is from the Pawlett Hams and the management of the Viridor credits landfill biodiversity offset site established in 2004. A key goal in managing the 100 ha site was to simplify WLM and farm enterprise. Through cooperative working land parcels that frequently flood have been taken out of agricultural production and have reverted back to marsh whilst in drier areas farm enterprises have been spatially reorganised. The principal mechanism to promote more coherent farm businesses was land swaps. Flexible management of the initial offset site proved a success and other farmers joined it. Today the entire 350 ha Pawlett Hams is managed jointly.

Interest in the management of the Pawlett Hams led to a one line inclusion in the SL\&M FAP (2014: 8) to "examine innovative mechanisms such as developing a Community Land Management Trust to support a Land Swap / Transfer / Purchase Scheme". Such Cooperation in the wider SL\&M would be necessary to restore large volume floodplain storage and to restore wetlands.

Now need to do more NFM in the lowlands, i.e. connect to floodplain. Grey Lake there is a regulatory structure to enable water to be stored on the floodplain. [Workshop 2] 
Our second example is partnering between lowland farmers and conservation NGOs. Latent Conflict reached a peak when farmers and others blamed NGOs for exacerbating the 2013/14 floods. To meet its bird conservation objectives the RSPB raises winter water levels on its property and promotes seasonal inundation of floodplain land, thus diminishing floodwater storage capacity on floodplains after heavy rain. Additionally, the RSPB works with farmers neighbouring their property. In this arrangement, farmers are paid Countryside Stewardship payments from the Department of Environment, Food \& Rural Affairs (Defra) for management activities, including lower stocking densities and higher WLM that benefit bird outcomes. This specific 'payments for ecosystem services scheme' (PES, Jack et al. 2008) is somewhat contentious as higher WLM is seen to reduce floodplain floodwater storage capacity.

Research funded by SDBC helped to lessen this Conflict. Stratford et al. (2015) demonstrated that RSPB direct and indirect management of the floodplain only marginally reduced floodplain storage and therefore was not a significant contributor to the 2013/14 floods. Research is likely to also play a role in scaling-up sFRM for instance on the effectiveness/opportunity/acceptability of NBS measures (Dadson et al., 2017; Broadmeadow et al., 2015; Holstead et al., 2014).

\subsubsection{Upstream-downstream connectivity}

This spatial dimension to latent Conflict is voiced in local fora. An example is upstreamdownstream landholder Conflict centred on the expansion of upland maize production incentivised by subsidy payments for anaerobic digestors. The perception is that increased maize production has augmented runoff, soil erosion and sediment supply, leading to silting and narrowing of receiving rivers and augmenting overland water flows increasing flood risk both in upland villages and in the lowland moors. An innovative response to this latent Conflict is Accommodation through new partnerships.

Since 2014 the SRA, FWAG-SW, the RSPB and SWT have supported the Hills to Levels (HtoL) programme (Royal Bath \& West of England Society, 2017). HtoL seeks to join up the catchment through influencing upland farmers' crop choice (no/less maize), land management choices (to harvest maize earlier/plant winter cover crops) and the adoption of NBS, such as berms, woody debris dams, small farm storage/wetlands, for the betterment of downstream communities and farmers.

\subsubsection{Whole of catchment connectivity}

Episodic, sometimes extensive, floods in all seasons are a natural phenomenon in the SL\&M that brought fertile silts to enrich floodplain soils. Yet with the arrival of intensive floodplain farming on drained soils and the expansion of communities on the floodplain and in rapid response catchments, floods are now often viewed as an external threat to farming, communities, and the way of life. In turn this leads to differences between groups 
around Competitive future visions, i.e. more dredging vs. efforts to increase floodplain storage. Yet, so too are there signs of a unified SL\&M vision. For instance participants' responses to Q2 (see Appendix) on what aspects of the SL\&M were important to them, were consistent across groups. The top five chosen, in order, were: Land for water storage, Bird conservation, Community identity, Livestock production, and Beautiful landscape. An explanation for a unified vision might be proximity, shared flooding experiences, and mutual trust (Seher and Löschner, 2018). We also suggest Acculturation is negotiated by vision-making and practiced in partnerships.

A local response to the 2013/14 flooding was the development of a vision for the SL\&M (Vision 2030, 2014). It envisions an FRM approach whereby the SL\&M community learns to live with flooding and continues to utilise floodplain storage. Vision 2030 was not a wholly reactive response to the 2013/14 floods as visioning exercises go back to 1997 . Furthermore, tangible examples of successful multi-functional management of floodplain wetlands, e.g. Southlake Moor (SDBC, 2011) likely reinforce this Acculturation process. Future plans to compensate landholders for floodplain storage (McCarthy et al., 2018) aligns with this vision and may overcome resistance to large-scale storage on connected floodplains (Thaler et al., 2017).

Whole catchment connectivity and wholescape thinking (Acreman et al., 2018) incorporates the interactions between the land, freshwater, estuaries and the sea. For instance, it is now more widely recognised that flooding in the lower Parrett around Bridgwater results from the interaction of high tides and high river flows. Furthermore, much of the sediment in the lower river is brought in on the incoming tide, rather than from upstream. Therefore, dredging of this sediment would be a very temporary measure and this knowledge has supported proposals for a tidal barrage near Bridgwater to prevent water and sediment surging up the river during high tides.

\section{Discussion}

In times of change FRM adaptation is key. There is some evidence that SL\&M stakeholders think in terms of reactive and anticipatory adaptation (Fankhauser et al., 1999) and had an awareness that more considered FRM approaches can easily fail in the face of calls for swift action after a flood (Wesselink et al., 2015).

Flood Action Plan (FAP) driving policy at a time of crisis. It is reactive - stress, break, fix response rather than calmly thinking about what is needed. Catchment Management Plan for the region and Option 6 was replaced by FAP overnight. Re-set everything overnight. [Workshop 2]

There was also appreciation of the intervals between floods as a time to reflect on FRM interventions (Penning-Rowsell et al., 2006).

Return to times when less stress to think about what to do. [Workshop 2]

A focus on this interval can illuminate the underpinning SPs that are central to the implementation of sFRM. Through this lens, tensions that lead to Conflict or Competition can be viewed less with alarm as they could lead to conflict resolution and social learning, 
i.e. Accommodation and Acculturation. Anticipatory and planned interventions in this period could support localised adaptation. We find SFRM interventions that facilitate more wholescape coordination include partnerships (Accommodation), vision-making (Acculturation) and innovators trialling new ways of working (Accommodation and Cooperation).

\subsection{SPs and social capital}

Data from the workshops and online survey provided some support for the conceptual model. We identified types of interventions and SL\&M examples that shift SPs from latent Conflict/Competition to Accommodation/Acculturation. Social capital may determine the success of partnerships and collaborative activities. For instance, the West Somerset flood group (WSfg) is a leader in Somerset.

Partnerships are not just about those employed by public services but also with communities. Marked contrasts across the county, e.g. West Somerset quite active FRM Group. [Workshop 2]

However, many communities are unlikely to have the "social and cultural capital and capacity" (Thaler and Priest, 2014, p423) or the procedural capacity (Thaler et al., 2017) to participate in new policy processes or the "willingness to take on the responsibility" Wesselink et al. (2015, p41). Therefore, if the government or the SRA wishes communities to take on additional SFRM responsibilities it would be useful to learn what makes particular flood groups successful.

The role of partnership groups, such as the WSfg, the SWMP and SCP, are as yet understudied. In an urban setting, Holt et al. (2012) found that a partnership group facilitated river restoration but struggled to generate a shared vision. They suggested it lacked legitimacy through its limited stakeholder diversity and that it would benefit from a process of vision-making. This is suggestive of the primacy of vision-making and indeed the code for Vision(-making) was the most frequently coded code across all six SPs. New research could address how visions are developed, how power influences which groups are heard and what is excluded, and the influence of wider political and economic conditions.

The 'maturity' of a group could be assessed against a framework (Pretty and Ward 2001). Such an exercise was undertaken for a farmer-led group in northern Australia (Brennan McKellar, 2015). It revealed that although it could be considered mature in more than half of the assessment categories, that it nevertheless was unable to influence the policy outcome. This may indicate that those areas in which it is was less mature, such as links with other groups and ability to generate internal and external solutions, might be critical. Again the role of vision-making is evident and the development of networking and group skills around conflict resolution and engagement.

Specific types of partner work might be particularly important for sFRM, e.g. learning from other partnerships (Acculturation, Assimilation) which is currently supported by the CaBA network, support for, and assessment of, innovative schemes such as land swaps and PES (Cooperation, Accommodation), and vision-making (Competition, Accommodation, Collaboration). The process of envisioning futures, especially when supported by pilots, e.g. 
HtoL, can and has, changed the narrative on wholescape thinking (Acculturation, mutualAssimilation). sFRM adaptation could be investigated across groups using longitudinal and comparative analysis to explore SPs, social capital and different group dynamics and pathways taken.

Another SL\&M group is the SWMP. Many Vision 2030 vision-makers are key Somerset stakeholders and regularly engage with how water and floods are managed through participation in the SWMP.

SWMP does not make decisions so the "management" is a bit misleading. Good forum to get information and share views. It gets reports from SRA. [Workshop 1]

This quote conforms with our participation in SWMP meetings; that is a place for what Thaler et al. (2017) identify as networking, debating and negotiating between different stakeholders. Variable attention was sometimes observed which might indicate latent inattention to certain issues; where the fullest attention was provided to sharing of information on hFRM projects. Nevertheless, groups supporting innovative schemes were invited to present learnings, including $H$ to $L$ and land swaps.

In researching social innovation, Grimm et al. $(2013,450)$ see SPs as foundational in valuing "social capital for building sustainable and resilient societies that have the capacity to act in an environment of permanent change." In conceptualising how SPs map to four SFRM interventions which all require social capital to deliver, we make a case for the fundamental SP elements of social capital. Social capital is the outcome of SPs even when SPs might be viewed as contrary to building social capital, e.g. Conflict and Competition. As researchers, we are not often equipped to deal with such SPs and might view, for instance, Conflict as the failure to build consensus, rather than viewing it as a process in building consensus or compromise. Greater reflection on SPs could be gained through long-term research collaborations with facilitators, groups, and networks.

\section{$5.2 \mathrm{sFRM}$ and devolved governance}

Identifying SPs that support sFRM interventions is one part of adaptation. Adaptation ideally needs to be planned and funded. A tangible outcome of vision-making in the SL\&M is the formation of the SRA. It may be anticipated that the SRA will facilitate greater coordination that will underpin wholescape thinking (Acreman et al., 2018). Perceptions of its role are mostly positive and demonstrate the importance placed on authorities working together with stakeholders.

Now SRA FRM is starting to work. First time all authorities are working together. [Workshop 1]

However, there were also more circumspect attitudes towards the SRA.

... SRA needs to be de-politicised it needs and independent chair, its actions need to be seen as non-political or else the SRA will lose credibility, not only with its partners but the public as we move towards precepting. [Online] 
Whereas, Penning-Rowsell and Johnson (2015, p140) found little evidence that real power has been devolved in England only of "devolved responsibility". The newly created SRA has devolved power, responsibility and funding. It prioritises local FRM investments using locally-raised funds through the Council Tax precept. This was viewed as an innovation in the workshop and online responses.

Money has been brought in. Prior to the flood the big issue was there was no money. Raising local money is ground-breaking. The precept is unique. [Workshop 2]

Participants also stated that local funding to support long-term planning is needed for other institutions and not just the SRA.

Also need consistent long-term funding streams for IDB, SRA, NE, SWT, FWAG-SW. [Workshop 2]

The SRA funds local flood groups. For example, through small-scale investments in flood preparedness equipment and flood alleviation schemes in West Somerset, where flooding is a very local issue affecting a few properties due to, for example, blockage of drains and ditches. Here major engineering works to reduce flood risk are not considered financially viable and may not be effective. Instead, SRA investment has provided local people with protective clothing, portable lights and equipment (such as rakes and shovels) so that they can solve these problems themselves very rapidly after heavy rainfall. Such interventions have also engendered a spirit of community empowerment, stewardship, and participation.

\subsection{Transferability}

Flooding across the UK in early 2020 demonstrates that FRM is a national issue. Almost all the issues we explored in our case study have been discussed at many locations.

Interactions between flooded residents and authorities has exhibited Coordination where temporary flood barriers and sandbags have stopped flooding or warnings/life boats have helped people escape, and Conflict where agencies have been blamed for lack of planning or investment in flood infrastructure. Acculturation with wholescape planning is evident with proposals for catchment-scale planning. Other areas that are particularly flood-prone, such as lower Severn Valley will benefit from lessons of SRA Coordination particularly community engagement and improving the authority/community participation. Although, it is not possible to simply transfer remedies from the SL\&M to another locality, where for example tree planting or peat restoration may be more appropriate; greater appreciation for the underlying SPs upon which local SFRM interventions are founded raises the profile of individual innovators and group activity such as vision-making, conflict resolution, and partnering.

\section{Conclusions}

Flooding is a perennial problem and whilst hard engineering may be required in some locations, other sFRM solutions may be complementary, more cost-effective in some localities and crucially also foster wholescape thinking. In times of change the potential is that sFRM might contribute to more resilient solutions, where responsibilities are shared, communities engaged, and novel solutions trialled. Furthermore, FRM policy that is 
supportive of SP-oriented adaption around the capacity to negotiate, question, learn, and experiment, can build many partnerships and community cohesion around a new vision for managing the interactions across the land, freshwater, estuaries and the sea.

\section{Acknowledgements}

Funding: This work was supported by the European Union's Horizon 2020 research and innovation programme under the Marie Skłodowska-Curie grant agreement No 659449, the Natural Environment Research Council (ceh020005 Natural Capital) and the Australian Research Council under Grant Number LP130100498. We are grateful for invitations to join the SWMP meetings, for their help with distributing invitations to the workshops and survey, and to local groups for meeting with us.

\section{References}

Acreman, M.C., Booker, D.J., Riddington, R. (2003). Hydrological impacts of floodplain restoration: a case study of the river Cherwell, UK, Hydrology and Earth System Sciences, 7, 1, 75-86

Acreman, M.C., Harding, R.J., Lloyd, C., McNamara, N.P., Mountford, J.O., Mould, D.J., Purse, B.V., Heard, M.S., Stratford, C.J., Dury, S. (2011). Trade-off in ecosystem services of the Somerset Levels and Moors wetlands Hydrological Sciences Journal. 56, 8, 1543-1565.

Acreman, M.C., Holden, J. (2013). Do wetlands reduce floods? Wetlands, 33:773-786

Acreman, M., Maltby, E., Maltby, A., Bryson, P., Bradshaw, N. (2018). Wholescape thinking: towards integrating the management of catchments, coast and the sea through partnerships - a guidance note Natural Capital Initiative, London. www.naturalcapitalinitiative.org.uk

Bardis, P.D. (1979). Social interaction and social processes, Social Science, 54(3): 147-167.

Brennan McKellar, L.E., Bark, R.H., Watson, I. (2015). Agricultural transition and land use change: Considerations in the development of irrigated enterprises in the rangelands of northern Australia, The Rangelands Journal, 37(5) 445-457. DOI: 10.1071/RJ14129.

Broadmeadow, S., Thomas, H., Nisbet, T. (2015). Opportunity mapping for woodland creation to reduce diffuse water pollution and flood risk in England and Wales, Forest Research, March 2014.

Bullock A., Acreman, M.C. (2003). The role of wetlands in the hydrological cycle, Hydrology and Earth System Sciences, 7,3, 75-86.

Corbin, J., Strauss, A. L. (2008). Basics of qualitative research (3rd ed.). Thousand Oaks, CA: Sage.

Dadson, S., Hall, J., Murgatroyd, A., Acreman, M., Bates, P., Beven, K., Heathwaite , L., Holden, J., Holman, I., Lane, S., O'Connell, E., Penning-Rowsell, E., Reynard, N., Sear, D., Thorne, C., Wilby, R. (2017). A restatement of the natural science evidence concerning 
catchment-based "natural" flood management in the United Kingdom. Proceedings of the Royal Society $A$

Defra (2013). Catchment Based Approach: Improving the quality of our water environment, UK. Available at: https://www.gov.uk/government/publications/catchment-basedapproach-improving-the-quality-of-our-water-environment.

Duranel, A., Acreman, M.C., Stratford, C., Thompson, J.R., Mould, D. (2007). Assessing hydrological suitability of the Thames floodplain for species-rich meadow restoration, Hydrology and Earth System Sciences 11, 1, 170-179.

Fankhauser, S., Smith, J.B., Tol, R.S.J. (1999). Weathering climate change: some simple rules to guide adaptation decisions. Ecological Economics, 3: 67-78.

Grimm, R., Fox, C., Baines, S., Albertson, K. (2013). Social innovation, an answer to contemporary societal challenges? Locating the concept in theory and practice. Innovation: The European Journal of Social Science Research, 26(4): 436-455.

HM Government (2016). National Flood Resilience Review. September 2016. Crown copyright 2016.

Holstead, K.L., Kenyon, W., Rouillard, J.J., Hopkins, J., Galán-Díaz, C. (2014). Natural flood management from the farmer's perspective: criteria that affect uptake, Journal of Flood Risk Management, DOI: 10.1111/jfr3.12129

Holt, A. R., Moug P., Lerner, D.N. (2012). The network governance of urban river corridors, Ecology and Society, 17(4): 25. http://dx.doi.org/10.5751/ES-05200-170425

Jack, B.K., Kouskya, C., Simsa, K.R.E. (2008). Designing payments for ecosystem services: Lessons from previous experience with incentive-based mechanisms. PNAS 10, 5, 28, 9465-947.

McCarthy, S., Viavattene, C., Sheehan, J., Green, C. (2018). Compensatory approaches and engagement techniques to gain flood storage in England and Wales, Journal of Flood Risk Management, 11: 85-94.

Miao, Q., D. Popp (2014). Necessity as the mother of invention: Innovative responses to natural disasters, Journal of Environmental Economics and Management, 68: 280-295.

Morris, J., Brewin, P. (2014). The impact of seasonal flooding on agriculture: the spring 2012 floods in Somerset, England. Journal of Flood Risk Management 7:128-140.

NAO (2014). Strategic flood risk management. Report by the Comptroller and Auditor General. National Audit Office, HC 780 Session 2014-15 5 November 2014.

Natural England (2013). National Character Area profile: 142: Somerset Levels and Moors. Catalogue Code: NE451. ISBN: 978-1-78367-008-6.

Penning-Rowsell, E., Johnson, C., Tunstall, S. (2006). 'Signals' from pre-crisis discourse: Lessons from UK flooding for global environmental policy change? Global Environmental Change, 16: 323-339. 
Penning-Rowsell, E., Johnson, C. (2015). The ebb and flow of power: British flood risk management and the politics of scale. Geoforum, 62: 131-142.

Porter J., Demeritt, D. (2012). Flood-risk management, mapping, and planning: the institutional politics of decision support in England, Environment and Planning A, 44: 2359-2378.

Pretty, J., Ward, H. (2001). Social Capital and the Environment, World Development, 29(2), 209-227.

Royal Bath \& West of England Society (2017). Hills to Levels, http://www.hillstolevels.co.uk/ Accessed May 30, 2017.

SDBC (2011). Southlake Moor Favourable Condition Project. http://www.somersetdrainageboards.gov.uk/media/Southlake-Moor-Project-ReportParrett-IDB-June-11.pdf accessed August 11, 2017.

SDC (2014). Sedgemoor District Council: Community Infrastructure Levy Charging Schedule, Adopted July 2014. Accessed November 4, 2016.

http://www.sedgemoor.gov.uk/CHttpHandler.ashx?id=15350\&p=0

Seher, W., Löschner, L. (2018). Balancing upstream-downstream interests in flood risk management: experiences from a catchment-based approach in Austria. Journal of Flood Risk Management, 11:56-65.

SL\&M FAP (2014). The Somerset Levels and Moors Flood Action Plan: A 20 year plan for a sustainable future.

https://somersetnewsroom.files.wordpress.com/2014/03/20yearactionplanfull3.pdf Accessed November 17, 2016.

Smith A., Porter J.J., Upham, P. (2016). "We cannot let this happen again": reversing UK flood policy in response to the Somerset Levels floods, 2014, Journal of Environmental Planning and Management, DOI: 10.1080/09640568.2016.1157458

SRA (2017). Somerset Rivers Authority, http://www.somersetriversauthority.org.uk/floodrisk-work/ Accessed May 30, 2017.

SRA (2015). Somerset Economic Impact Assessment of the Winter 2013/14 Flooding. 285333KV-HLT/1/3 Final. July, 2015.

Staveren, M.F., van Tatenhove, J.P.M. (2016). Hydraulic engineering in the social-ecological delta: understanding the interplay between social, ecological, and technological systems in the Dutch delta by means of 'delta trajectories'. Ecology and Society, 21(1):8

Stratford, C., Brewin, P., Acreman, M., Mountford, O. (2015). A simple model to qualify the potential trade-off between WLM for ecological benefit and flood risk, Ecohydrology \& Hydrobiology, 15(3), 150-159. https://doi.org/10.1016/j.ecohyd.2015.06.002

Stratford, C., Miller, J., House, A., Old, G., Acreman, M., Dueñas-Lopez, M. A., Nisbet, T., Newman, J., Burgess-Gamble, L., Chappell, N., Clarke, S., Leeson, L., Monbiot, G., Paterson, J., Robinson, M., Rogers, M., Tickner, D. (2017). Do trees in UK-relevant river 
catchments influence fluvial flood peaks? NERC Centre for Ecology \& Hydrology, Wallingford, UK. 46pp.

Thaler, T., Priest, S. (2014). Partnership funding in flood risk management: new localism debate and policy in England, Area, 46(4): 418-425.

Thaler, T., Löschner, L., Harmann, T. (2017). The introduction of catchment-wide cooperations: Sclar reconstructions and transformation in Austria in flood risk management, Land Use Policy, 68: 563-573.

UK Government (2014). New action plan to protect Somerset from flooding. UK Government.

Vision 2030 (2014). The Somerset Levels and Moors Task Force "Vision for the Somerset Levels and Moors in 2030." http://www.rspb.org.uk/community/ourwork/b/southwest/archive/2014/02/03/conse nsus-on-somerset-levels-39-future-will-underpin-action-on-flooding.aspx

Yin, R.K. (2009). Case Study Research: Design and Methods. 4th Edition. Sage Publications, Thousand Oaks, CA.

Wesselink, A. et al. (2015). Trends in flood risk management in deltas around the world: Are we going 'soft'? International Journal of Water Governance, 4: 25-46.

\section{Appendix}

Q1: [Open-ended] Imagine it is 2030 and you are travelling around the Somerset Levels \& Moors and are delighted with what you find. What do you find?

Q2: [Closed-ended] What is most important to you? Please pick 4. The options are: Livestock production, Biofuels, art and culture, Archaeology, Recreation, Beautiful landscape, Land for water storage, Arable production, New houses, Community identity, Bird conservation.

Q3: [Open-ended] What information do we have / do we need to make a water management / land management decisions?

Q4: [Open-ended] How do you feel about monetary values? / Who benefits / loses from using monetary values? What alternatives are there to monetary values?

Q5: [Open-ended] Do you think the current approach to flood risk management is working? Is there a better approach to flood risk management?

Q6: [Open-ended] How important are partnerships in flood risk management? 